\title{
Pengaruh Mobilisasi Dini terhadap Involusi Uterus pada Ibu Post Partum di Wilayah Kerja Puskesmas O Mangunharjo Kabupaten Musi Rawas
}

\author{
Nuril Absari ${ }^{1}$, Desty Nova Riyani ${ }^{2}$ \\ Nurilsari23@Gmail.com \\ Program Studi D.IV Kebidanan STIKES Tri Mandiri Sakti Bengkulu \\ J1 Hibrida Raya no 03 Bengkulu \\ Telp 081273984868
}

\begin{abstract}
Abstrak
Penurunan ukuran uterus yang cepat pada ibu post partum direfleksikan dengan perubahan lokasi uterus yaitu uterus turun dari abdomen dan kembali menjadi organ panggul. Penelitian ini bertujuan untuk mempelajari pengaruh mobilisasi dini terhadap involusi uterus pada ibupost partum di Wilayah Kerja Puskesmas O MangunharjoKabupatenMusi Rawas. Penelitian ini menggunakan pendekatan Pre Eksperimental (The Static Group Comparation Design). Populasi dalam penelitian ini adalah seluruh ibu post partum bulan Juli-Agustus 2018 di wilayah kerja puskesmas O Mangunharjo Kabupaten Musi Rawas diperoleh 30 sampel terdiri dari 15 orang dilakukan mobilisasi dini dan 15 orang tidak mobilisasi dini diambil mengunakan purposive sampling. Pengumpulan data dalam penelitian ini yaitu menggunakan data primer dengan menyebarkan kuesioner. Analisis data dilakukan dengan uji normalitas data, uji normalitas data dan Uji Independent samples T Test (uji t). Hasil penelitian didapatkan: (1) Diperoleh nilai ratarata penurunan involusi utari pada kelompok yang diberikan mobilisasi dini adalah 8,02 hari; (2) Diperoleh nilai rata-rata penurunan involusi utari pada kelompok yang tidak diberikan mobilisasi dini adalah 9,65 hari dan (3) Terdapat pengaruh mobilisasi dini terhadap involusi uterus pada ibu post partum di Wilayah Kerja Puskesmas O Mangunharjo Kabupaten Musi Rawas. Diharapkan pada pihak puskesmas untuk dapat melakukan pelatihan teknik mobilisasi dini pada ibu hamil, meningkatkan kualitas kelas ibu hamil serta meningkatkan pengetahuan ibu hamil melalui penyuluhan, pemasangan poster dan pemasangan spanduk di wilayah kerja puskesmas dan tempat keramaian sehingga pengetahuan ibu meningkat. Pada bidan diharapkan dapat menjelaskan kepada ibu hamil pada saat ANC dan pada ibu bersalin pada saat melakukan persalinan untuk menjelaskan pentingnya mobilisasi dini agar dapat mempercepat penurunan pundus uteri setelah ibu bersalin dan pentingnya melakukan kunjungan kelas ibu damil dan keteraturan melakukan kunjungan ANC.
\end{abstract}

Kata Kunci: Mobilisasi Dini, Involusi Uterus

\begin{abstract}
The purpose of this study is to determine Effect of Early Mobilization to Involution Utery on Postpartum mother in Area of O Mangunharjo Primary Health Care MusiRawasDistrict.This study used pre experiment (The static group comparation design). Population in this study were all Postpartum mother in Area of $O$ Mangunharjo Primary Health Care MusiRawas District in month of July-August 2018 obtained 30 sample consist of 15 people doing Early Mobilization and 15 did not doing Early Mobilization. Collecting data in this study used primary data with spreaded questionnaire. Data analysis used normality data, Independent samples $T$ Test.The result of this study showed: (1) Obtained value average decreased Involution Utery on group who were doing Early Mobilization were 8,02 days (2) Obtained value average decreased Involution Utery on group who were doing Early Mobilization were 9,65 days 93) there is Effect of Early Mobilization to Involution Utery on Postpartum mother in Area of $O$ Mangunharjo Primary Health Care MusiRawas District.
\end{abstract}

Keywords: Early Mobilization, Involution Utery, Postpartum mother 


\section{Pendahuluan}

Kematian ibu adalah kematian seorang wanita terjadi saat hamil, bersalin, atau 42 hari setelah persalinan.Pada laporan WHO yang berjudul Strategies toward ending preventable maternal mortality (EPMM), target angka kematian ibu pada tahun 2030 pada negara yang memiliki AKI kurang dari 420 di tahun 2010, harus menurunkan AKI sekitar 2/3 dari angka AKI 2010 pada tahun 2030 mendatan $^{1}$.

Berdasarkan data Survey

Demografi Kesehatan Indonesia (SDKI) tahun 2012 menunjukkan peningkatan AKI yang signifikan yaitu menjadi 359 kematian ibu per 100.000 kelahiran hidup. AKI kembali menujukkan penurunan menjadi 305 kematian ibu per 100.000 kelahiran hidup berdasarkan hasil Survei Penduduk Antar Sensus (SUPAS) $2015^{2}$.

Di Indonesia Tahun 2016 terdapat $80,61 \%$ ibu hamil yang menjalani persalinan dengan ditolong oleh tenaga kesehatan dan dilakukan difasilitas pelayanan kesehatan di Indonesia. Secara nasional, indikator tersebut telah memenuhi target Renstra sebesar 77\%. Namun demikian masih terdapat 19 provinsi $(55,9 \%)$ yang belum memenuhi target tersebut. Provinsi NTB memiliki capaian tertinggi sebesar $100,02 \%$, diikuti oleh DKI Jakarta sebesar 97,29\%, dan Kepulauan Riau sebesar 96,04\%. Sedangkan Provinsi Maluku Utara memiliki capaian terendah sebesar $17,79 \%$, diikuti oleh Maluku sebesar 25,71\%, dan Papua sebesar $39,18 \%{ }^{2}$

Hasil survey awal yang dilakukan pada tanggal 6 Maret 2018, dari 5 orang ibu bersalin yang tidak dilakukan mobilisasi dini terdapat 3 orang mengalami penurunan involusi uterus pertengahan antara pusat dan simpisis selama 8 hari dan 2 orang mengalami penurunan involusi uteruspertengahan antara pusat dan simpisis selama 9 hari.

Rumusan masalah penelitian ini "apakah ada pengaruh mobilisasi dini terhadap involusi uterus pada ibu post partum di wilayah kerja puskesmas $\mathrm{O}$ Mangunharjo Kabupaten Musi Rawas?". Tujuan penelitian untuk mempelajari pengaruh mobilisasi dini terhadap involusi uterus pada ibu post partum di wilayah kerja puskesmas $\mathrm{O}$ Mangunharjo Kabupaten Musi Rawas

\section{Metode Penelitian}

Jenis penelitian ini adalah Pre Eksperimental (The Static Group Comparation Design). Pada rancangan ini, ada kelompok yang diberikan treatmen eksperimental (ibu post partum yang diberikan tindakan mobilisasi dini kemudian dilakukan observasi involusi uterus) dan ada kelompok lainnya yang tak diberikan treatmen(ibu post partum yang tidak diberikan tindakan mobilisasi dini kemudian dilakukan observasi involusi uterus). Populasi yang dalam penelitian ini adalah seluruh ibu post partumbulan Juli-Agustus 2018 di wilayah kerja puskesmas $\mathrm{O}$ Mangunharjo Kabupaten Musi Rawas. Sasaran ibu pospartum pada bulan Mei-Juni 2018 sebanyak 123 ibu postpartum. Analisis data mengunakan analisis univariat dan bivariat.

\section{Hasil dan Pembahasan}

\section{a. Analisis Univariat}

Dilakukan untuk mengetahui gambaran rata-rata involusi uterus pada ibu bersalin di Wilayah Kerja Puskesmas O Mangunharjo Kabupaten Musi Rawas Utara yaitu sebagai berikut:

Tabel 1

Gambaran Rata-Rata Involusi Uterus pada Ibu Bersalin di Wilayah Kerja Puskesmas O Mangunharjo Kabupaten MusiRawas Utara 
Jurnal Kebidanan Harapan Ibu Pekalongan

\begin{tabular}{ccc}
\hline Perlakukan & F & $\begin{array}{c}\text { Mean } \\
\text { Penurunan } \\
\text { Uterus \% }\end{array}$ \\
\hline Mobilisasi Dini & 15 & 8,02 \\
\hline $\begin{array}{c}\text { Tidak Mobilisasi } \\
\text { Dini }\end{array}$ & 15 & 9,65 \\
\hline Jumlah & 30 & 100,0 \\
\hline
\end{tabular}

Berdasarkan Tabel 1 di atas diperoleh nilai rata-rata untuk kelompok sampel yang diberi mobilisasi dini adalah rata-rata involusi uteri adalah 8,02 hari dan yang tidak dilakukan mobilisasi dini rata-rata involusi uteri adalah 9,65 hari.

\section{b. Analisis bivariat}

Dilakukan untuk mengetahui pengaruh mobilisasi dini terhadap involusi uterus pada ibu post partum di wilayah kerja puskesmas $\mathrm{O}$ Mangunharjo Kabupaten Musi Rawas dengan menggunakan uji dua sampel bebas (Independent-Samples T Test).

Tabel2

Pengaruh Mobilisasi Dini Terhadap Involusi Uterus Pada IbuPost Partum di Wilayah Kerja Puskesmas O Mangunharjo Kabupaten Musi Rawas.

\begin{tabular}{|c|c|c|c|c|}
\hline Perlakukan & $\mathrm{F}$ & Mean & $\mathrm{t}$ & $\mathrm{p}$ \\
\hline $\begin{array}{l}\text { Mobilisasi } \\
\text { Dini }\end{array}$ & 15 & 8.02 & \multirow[t]{2}{*}{$\begin{array}{c}- \\
6,135\end{array}$} & \multirow[t]{2}{*}{0,000} \\
\hline $\begin{array}{c}\text { Tidak } \\
\text { Mobilisasi } \\
\text { Dini }\end{array}$ & 15 & 9.65 & & \\
\hline Jumlah & 30 & & & \\
\hline
\end{tabular}

Hasil analisis Independent Samples $t$ Test didapat nilai $\mathrm{t}=-6,135$ dengan nilai $p=0,000<\alpha=0,05$, maka Ho ditolak dan Ha diterima. Jadi ada Pengaruh Mobilisasi Dini Terhadap Involusi Uterus Pada Ibu Post Partum di Wilayah Kerja Puskesmas O Mangunharjo Kabupaten Musi Rawas.

Hasil penelitian rata-rata involusi uteri pada ibu bersalin yang dilakukan mobilisasi dini adalah 8,02 hari artinya dari 15 ibu hamil yang dilakukan tindakan mobilisasi dini rata-rata penurunan fundus uteri setelah proses persalinan adalah pada hari ke delapan.

Hasil penelitian ini sejalan
dengan $(2015)^{3}$, menunjukkan bahwa sebanyak $73,6 \%$, rata-rata mobilisasi ibu nifas adalah 64,34 menit. Hal ini masuk kategori kurang baik.Mobilisasi dini paling cepat yaitu 20 menit dan paling lambat 120 menit.Cepat lambatnya seorang ibu post partum melakukan mobilisasi dini akan berpengaruh pada pengeluaran lochea, proses involusio, aktivitas organ gastrointestinal, organ perkemihan dan sirkulasi darah.

Menurut Manuaba (2013) ${ }^{4}$, mobilisasi dini memiliki beberapa tujuan antara lain sebagai berikut mempertahankan fungsi tubuh, memperlancar peredaran darah, membantu pernafasan menjadi lebih baik, mempertahankan tonus otot, memperlancar eliminasialvi dan urine, Mengembalikan aktivitas tertentu, sehingga pasien dapat kembali normal dan atau dapat memenuhi kebutuhan gerak harian dan memberikan kesempatan perawatdan pasien berinteraksi dan berkomunikasi.

Hasil penelitian rata-rata involusi uteri pada ibu bersalin yang dilakukan mobilisasi dini adalah 9,65 hari artinya dari 15 ibu hamil yang dilakukan tindakan mobilisasi dini rata-rata penurunan pundus uteri setelah proses persalinan adalah pada hari ke sembilan.

Hasil penelitian ini sejalan dengan penelitian Apriana (2015) menunjukkan rata-rata tinggi fundus uteri pada ibu post partum spontan yang tidak melakukan mobilisasi dini adalah sebesar $28.55 \mathrm{~cm}$ dan ibu post partum spontan yang melakukan mobilisasi dini adalah $12.45 \mathrm{~cm}$. Hasil uji statistik ada pengaruh antara mobilisasi dini terhadap penurunan tinggi fundus uteri pada ibu post partum spontan di RSUD Tugurejo Semarang. 
Menurut Ambarwati \& Wulandari (2014) $)^{6}$, involusi dapat diamati dari luar dengan memeriksa fundus uteri sebagai berikut: Segera setelah melahirkan, tinggi fundus uteri $2 \mathrm{~cm}$ dibawah pusat, 12 jam kemudian kembali $1 \mathrm{~cm}$ diatas pusat dan menurun kira-kira $1 \mathrm{~cm}$ setiap hari. Pada hari ke dua setelah persalinan tinggi fundus uteri $1 \mathrm{~cm}$ dibawah pusat. Pada hari ke 3-4 tinggi fundus uteri $2 \mathrm{~cm}$ dibawah pusat. Pada hari 57 tinggi fundus uteri setengah pusat sampai simpisis. Pada hari ke 10 tinggi fundus uteri tidak teraba.

Berdasarkan hasil analisis Independent Samples Test pengaruh mobilisasi dini terhadap involusi uterus pada ibu post partum di Wilayah Kerja Puskesmas O Mangunharjo Kabupaten Musi Rawas. Hasil penelitian ini sejalan dengan penelitian yang dilakukan oleh hasil penelitian Prihartini (2014) ${ }^{7}$, menunjukkan bahwa mobilisasi dini terhadap penurunan TFU pada ibu nifas adalah sengat besar yaitu $18 \mathrm{ibu}$ nifas $(90 \%)$ diantaranya mengalami penurunan TFU meskipun masih ada 2 ibu nifas (10\%) yang tetap TFU. Hasil observasi peneliti menunjukkan setelah melakukan mobilisasi dini ibu nifas mengalami penurunan TFU. Ini menunjukkan mobilisasi dapat mempengaruhi penurunan TFU pada ibu nifas setelah 2 jam post partum.

Hasil penelitian yang dilakukan pada ibu bersalin di Puskesmas $\mathrm{O}$ Mangunharjo setalah diberikan perlakukan selama mobilisasi dini diperoleh data rata-rata penurunan involusi uteri pada ibu yang dilakukan mobilisasi dini lebih cepat dari yang tidak dilakukan mobilisasi dini. Hasil tersebut menunjukkan bahwa mobilisasi dini dapat mempercepat penurunan pundus uteri pada ibu bersalin.

Hasil penelitian ini sejalan dengan penelitian Hadi $(2014)^{8}$, bahwa peran mobilisasi terhadap involusi uteri dijelaskan sebagai berikut, mobilisasi meningkatkan kontraksi dan retraksi dari otot-otot uterus setelah bayi lahir. Kontraksi dan retraksi ini diperlukan untuk menjepit pembuluh darah yang pecah akibat pelepasan plasenta. Dengan adanya kontraksi dan retraksi yang terus menerus ini menyebabkan terganggunya peredaran darah dalam uterus mengakibatkan jaringan otot kekurangan zat-zat yang diperlukan, sehingga ukuran jaringan otototot tersebut menjadi kecil. Dengan demikian ibu yang melakukan mobilisasi dini mempunyai penurunan fundus uteri lebih cepat.

\section{Kesimpulan}

Dapat disimpulkan bahwa nilai rata-rata penurunan involusi utari pada kelompok yang diberikan mobilisasi dini adalah 8,02 hari. Dan diperoleh nilai rata-rata penurunan involusi utari pada kelompok yang tidak diberikan mobilisasi dini adalah 9,65 hari. Terdapat pengaruh mobilisasi dini terhadap involusi uterus pada ibu post partum di Wilayah Kerja Puskesmas O Mangunharjo Kabupaten Musi Rawas.

\section{Daftar Pustaka}

[1] Islami, D.R. (2017). Perencanaan program keps (kartu edukasi pendamping siaga) dan mekanisme pengelolaannya terkait angka kematian ibu (aki). Makalah Program Pasca Sarjana ITB

[2] Kemenkes RI. (2017). Profil kesehatan Indonesia. Jakarta: Kementerian Kesehatan RI.

[3] Rofi'ah, S. (2015). Faktor-faktor yang berhubungan dengan Penurunan Tinggi Fundus Uteri pada Ibu Nifas 6 jam Post Partum. Jurnal Riset Kesehatan Vol. 4 No. 2.

[4] Manuaba, I.B.G, (2013). Ilmu Kebidanan, Penyakit Kandungan, dan Keluarga 
Berencana Untuk Pendidikan Bidan. Jakarta: EGC

[5] Apriana, R (2015). Pengaruh mobilisasi dini terhadap penurunan tinggi fundus uteri pada ibu post partum spontan di RSUD Tugurejo Semarang. Jurnal MUSWIL IPEMI

[6] Wulandari, D. 2010. Asuhan Kebidanan Nifas. Yogyakarta: Nuha Medika

[7] Prihartini, S.D (2014). Pengaruh mobilisasi dini terhadap penurunan tinggi fundus uteri pada ibu nifas di paviliun melati RSUD Jombang. Jurnal Edu Health, Vol. 4 No. 2
[8] Hadi, Y. 2014.Faktor- faktor yang berhubungan dengan involusi uterus pada ibu post partum di wilayah kerja puskesmas Ketapang Lampung Utara. Jurnal Kesehatan Metro Sai Wawai Volume VII No.2 